\title{
Folate-targeted paclitaxel-conjugated polymeric micelles inhibits pulmonary metastatic hepatoma in experimental murine $\mathrm{H} 22$ metastasis models
}

This article was published in the following Dove Press journal:

International Journal of Nanomedicine

23 April 2014

Number of times this article has been viewed

\author{
Yan Zhang' \\ Hui Zhang ${ }^{2}$ \\ Wenbin $\mathrm{Wu}^{2}$ \\ Fuhong Zhang ${ }^{3,4}$ \\ Shi Liu $^{3}$ \\ Rui Wang ${ }^{3}$ \\ Yingchun Sun' \\ Ti Tong' \\ Xiabin Jing ${ }^{3}$ \\ 'Department of Thoracic Surgery, The \\ Second Hospital of Jilin University, \\ Changchun, Jilin, People's Republic \\ of China; ${ }^{2}$ Department of Thoracic \\ Surgery, Xuzhou Central Hospital, \\ Xuzhou, Jiangsu, People's Republic \\ of China; ${ }^{3}$ State Key Laboratory \\ of Polymer Physics and Chemistry, \\ Changchun Institute of Applied \\ Chemistry, Chinese Academy of \\ Sciences, Changchun, Jilin, People's \\ Republic of China; ${ }^{4}$ Department of \\ Otolaryngology, The First Hospital of \\ Lanzhou University, Lanzhou, Gansu, \\ People's Republic of China
}

Correspondence: Ti Tong

Department of Thoracic Surgery, Second Hospital of Jilin University, No. 218,

Ziqiang Street, Changchun, Jilin I3004I,

People's Republic of China

Tel +8643 I 88782536

Fax +86 43I 88782536

Email titong2012@।63.com

Xiabin Jing

State Key Laboratory of Polymer Physics and Chemistry, Changchun Institute of Applied Chemistry, Chinese Academy of Science, No.5625,

Renmin Street, Changchun, Jilin,

People's Republic of China

Tel +8643 I 85262775

Fax +8643185262775

Email xbjing@ciac.jl.cn
Abstract: Hepatocellular carcinoma shows low response to most conventional chemotherapies; additionally, extrahepatic metastasis from hepatoma is considered refractory to conventional systemic chemotherapy. Target therapy is a promising strategy for advanced hepatoma; however, targeted accumulation and controlled release of therapeutic agents into the metastatic site is still a great challenge. Folic acid (FA) and paclitaxel (PTX) containing composite micelles (FA-M[PTX]) were prepared by coassembling the FA polymer conjugate and PTX polymer conjugate. The main purpose of this study is to investigate the inhibitory efficacy of FA-M(PTX) on the pulmonary metastasis of intravenously injected murine hepatoma 22 (H22) on BALB/c mice models. The lung metastatic burden of $\mathrm{H} 22$ were measured and tissues were analyzed by immunohistochemistry and histology (hematoxylin and eosin stain), followed by survival analysis. The results indicated that FA-M(PTX) prevented pulmonary metastasis of H22, and the efficacy was stronger than pure PTX and simple PTX-conjugated micelles. In particular, the formation of lung metastasis colonies in mice was evidently inhibited, which was paralleled with the downregulated expression of matrix metalloproteinase- 2 and matrix metalloproteinase-9. Furthermore, the mice bearing pulmonary metastatic hepatoma in the FA-M(PTX) group gained significantly prolonged survival time when compared with others given equivalent doses of PTX of $30 \mathrm{mg} / \mathrm{kg}$. The enhanced efficacy of FA-M(PTX) is theoretically ascribed to the target effect of FA; moreover, the extensive pulmonary capillary networks may play a role. In conclusion, FA-M(PTX) displayed great potential as a promising antimetastatic agent, and the FA-conjugated micelles is a preferential targeted delivery system when compared to micelles without FA.

Keywords: pulmonary metastasis, folate receptor, paclitaxel, polymer-drug conjugate, targeted drug delivery

\section{Introduction}

Hepatocellular carcinoma (HCC) is currently one of the most common solid tumors and one of the leading causes of cancer-related death, which has a dismal overall prognosis, with more than $90 \%$ of affected individuals dying of the disease. ${ }^{1,2}$ Additionally, only about $20 \%$ of HCC patients are eligible for surgery, which is still the most effective treatment with curative potential. ${ }^{3}$ Furthermore, tumor metastasis is the primary cause of severe mortality, and pulmonary metastases account for over $50 \%$ of extrahepatic HCC metastases, more than $80 \%$ of which are advanced. ${ }^{4-6}$ Nevertheless, most chemotherapeutic agents show limited effectiveness and fail to improve patient survival. ${ }^{7-10}$ Moreover, HCC is inherently chemotherapy-resistant, which overexpresses multidrug-resistant genes such as MDRl $(P-g p)$ and the multidrug-resistance proteins. ${ }^{11-13}$ The adverse clinical course of most HCC patients 
underscores the need for more efficacious chemotherapies and the development of targeted strategies. ${ }^{14}$ Furthermore, cancer cells that have distributed to distant organs often remain dormant. ${ }^{15}$ Recently, the process of tumor metastasis has been thoroughly investigated and some pharmaceutical agents, including molecular target drugs, have been developed to inhibit a specific step of metastasis. ${ }^{16}$

It was reported that paclitaxel (PTX) inhibits the growth of liver cancer cells; ${ }^{17}$ however, the clinical application of PTX is limited for low water solubility and nonselective toxicity. Thanks to nanotechnology, the controlled release of anticancer agents could enhance their effective delivery, ${ }^{18}$ which may lead to an enhancement in both the intensity and duration of exposure of drugs at the target site. ${ }^{19}$ A Cremophor ${ }^{\circledR}$-free (BASF SE, Ludwigshafen, Germany) formulation of PTX nanoparticles called Abraxane ${ }^{\circledR}$ (Celgene Corporation, Summit, NJ, USA) has been approved by the United States Food and Drug Administration for recurrent metastatic breast cancer. ${ }^{20}$ To improve target efficiency and to reduce side effects, introducing target molecules, such as folic acid (FA), monoclonal antibodies (mAb225, and so on), and peptides into nanoparticles is necessary because they could recognize and bind to specific receptors that are unique to tumor cells. ${ }^{21-23}$ As an active targeting moiety and natural element, FA does not induce allergies as many proteins do; furthermore, it is overexpressed in carcinomas of the kidney, lung, and breast, with restricted expression in most normal tissues. ${ }^{24}$ Therefore, nanoparticles functionalized with FA can specifically promote their cancer cellular uptake through folate receptor (FR)-mediated endocytosis, and folate-decorated mixed polymeric nanoparticles are potential carriers for tumor-targeted drug delivery. ${ }^{25,26}$

To date, the therapeutic evaluation of PTX micelles on the pulmonary metastasis of hepatoma is of vital urgency. However, to the best of our knowledge, there has been little work done on the study of targeted therapy of FR-mediated PTX-conjugated micelles for pulmonary metastatic hepatoma in vivo. Based on these facts, the antitumor activity of the FA- and PTX-containing composite micelles was performed on hepatoma 22 (H22) cells both in vitro and in vivo. In detail, the cellular uptake of rhodamine B ( RhB)-labeled micelles by HeLa, H22, and nontumorigenic BEAS-2B cell lines, and their cellular viability as well as apoptosis were evaluated. Furthermore, the inhibition efficacy of the bifunctional PTX polymeric micelles on the pulmonary metastasis of intravenously injected $\mathrm{H} 22$ cells was investigated in vivo, including an immunohistochemistry (IHC), hematoxylin and eosin (HE) stain, and survival analysis, with a view to provide a theoretical basis for the clinical therapy of pulmonary metastatic HCC.

\section{Materials and methods Polymeric micelles}

Polymeric carriers as amphiphilic diblock copolymers poly(ethylene glycol)-block-poly(1-lactide-co-2-methyl-2-carboxyl-propylene carbonate) (MPEG-b-P[LA-co-MCC]) and poly(ethylene glycol)-block-poly(lactide-co-2,2-dihydroxymethylpropylene carbonate) (MPEG-b-P[LA-co-DHP]) for the conjugation of FA and PTX were prepared as previously reported in our laboratory. ${ }^{27-29} \mathrm{MCC}$ and DHP denote trimethylene carbonate units with pendant carboxyl $(\mathrm{COOH})$ and dihydroxyl $(\mathrm{OH})$ groups, respectively. Based on these works, FA- and PTX-containing mixed micelles (FA-M[PTX]), were prepared, and the formulas are shown in Table S1 and Figure S1. Dynamic light scattering was used again in this study to characterize the hydrodynamic size and poly-dispersity of M(PTX) and FA-M(PTX) in each preparation. The morphology of the micelles was evaluated by transmission electron microscope (TEM) (Philips CM120; Koninklijke Philips NV, Eindhoven, the Netherlands) as well.

\section{Cell culture}

The murine hepatoma cell line $\mathrm{H} 22$, human cervix epithelial carcinoma HeLa, and the human bronchial epithelial cell line BEAS-2B were obtained from the Shanghai Cell Center of Chinese Academy of Medical Science (Shanghai Institutes for Biological Sciences, Shanghai, People's Republic of China). The H22 and HeLa cells were cultured with FA-free Roswell Park Memorial Institute (RPMI) 1640 medium (Sigma-Aldrich, St Louis, MO, USA) with 1\% penicillin and streptomycin, and 10\% fetal bovine serum (FBS) (Gibco-BRL; Life Technologies, Carlsbad, CA, USA), while the BEAS-2B cells were incubated in serum-free medium; LHC-9 (Biofluids, Inc., Rockville, MD, USA) were incubated in a humidified incubator (SANYO Electric Co, Ltd, Moriguchi, Osaka, Japan) containing a 5\% $\mathrm{CO}_{2}$-humidified atmosphere at $37^{\circ} \mathrm{C}$.

\section{Cellular viability assay}

The cytotoxicity of PTX, M(PTX), and FA-M(PTX) to H22 cells was determined by cellular viability assay, as reported. ${ }^{30}$ In brief, cells were plated at $10^{4}$ cells/well in 96-well plates in FA-free RPMI 1640. The following day, the cells were treated with different forms of PTX at different gradient concentrations. At the desired time points of 12 hours, 24 hours, and 48 hours, trypan blue was used to measure the suspended 
H22 cellular death by counting the number of dead (blue) and live cells. The cellular viability assay was performed five times, independently, and the data was expressed as the mean \pm standard error (SE).

\section{Hoechst 33342/propidium iodide $(\mathrm{PI})$ double-stain assay}

The H22 cells were inoculated into a six-well plate with $5 \times 10^{5}$ cells per well. The following day, the drugs were added into the wells at the final equivalent PTX concentration of $100 \mathrm{ng} / \mathrm{mL}$. Apoptosis of the tumor cells after being incubated with drugs for 24 hours and 72 hours, respectively, was detected using a Hoechst 33342/PI apoptosis detection kit (GenScript USA Inc., Piscataway, NJ, USA) by FACSCalibur ${ }^{\mathrm{TM}}$ Flow Cytometer (BD, Franklin Lakes, NJ, USA), as reported. ${ }^{31}$ Apoptotic cells were positively stained only with Hoechst 33342, whereas necrotic/dead cells were positively stained with PI. The three quadrants could be assigned to normal cells (P2), apoptotic cells (P3), and necrotic cells (P4), expressed in histograms.

\section{Cellular uptake of rhodamine B-labeled micelles using flow cytometry}

Two kinds of micelles containing $\mathrm{RhB}$ were prepared by a solvent evaporation method, as previously reported. ${ }^{32}$ FA and $\mathrm{RhB}$ were conjugated to the same copolymer carrier. In detail, one is an RhB-containing and FA-free (f) copolymer (FA-f-micelles) poly(ethylene glycol)-b-poly(L-lactide-co2,2- dihydroxylmethyl-propylene carbonate/RhB) (PEGb-P [LA-co-DHP/RhB]), and the other is an RhB- and FA-containing composite micelle (FA-mixed micelles) prepared from a mixture of the FA-polymer conjugate, PEGb-P(LA-co-DHP/FA) and the RhB-containing copolymer PEG-b-P(LA-co-DHP/RhB), with a mass ratio of $1: 9$. The $\mathrm{RhB}$-labeled micelles were used for the evaluation of the presumed preferential uptake of the FA-containing micelles by tumor cells with overexpressed FR (HeLa and H22), compared to that of normal cells (BEAS-2B), and the differential uptake of the FA-mixed micelles/FA-f-micelles by these cells based on the theoretical FR-mediated endocytosis. The three cell lines were plated at $5 \times 10^{5}$ cells/well in six-well plates in different FA-free medium and they were incubated overnight. Then, the cells were divided into six groups (five samples for each) and incubated with $0.1 \%$ FA-f-micelles and FA-mixed micelles solutions, respectively, in renewed FBS- and FA-free medium for 2 hours at $37^{\circ} \mathrm{C}$. Then, the suspended cells of $\mathrm{H} 22$ and the adherent cells of HeLa and BEAS-2B were collected carefully with or without ethylenediaminetetraacetic acid-free trypsin by centrifugation (1,000 rpm, 5 minutes) and washed three times with cold phosphate buffered saline $\left(0^{\circ} \mathrm{C}-4^{\circ} \mathrm{C}\right)$. Then, the samples were adjusted to $10^{6}$ cells/tube and detected by flow cytometry (FCM) in 30 minutes.

\section{Establishment of models bearing pulmonary metastatic hepatoma}

Five- to 6-week-old female BALB/c mice weighing 20 22 g were obtained from the Institute of Laboratory Animals, Chinese Academy of Medical Science (Beijing, People's Republic of China) and raised in a specific-pathogen-free facility for in vivo experiments following Chinese government guidelines. All animal procedures were approved and controlled by the local ethics committee and carried out according to the guidelines of the Chinese law of protection of animal life. ${ }^{33}$ The mice were housed at $20^{\circ} \mathrm{C} \sim 22^{\circ} \mathrm{C}$, with a relative humidity of $40 \% \sim 60 \%$ and a 12 -hour light/12-hour dark cycle. H22 cells were collected and injected into the abdomen of a BALB/c mouse for 10 days. When the enlarged abdomen was observed, the ascites was harvested and washed with $0.9 \%$ saline for three times in 30 minutes at $22^{\circ} \mathrm{C}$. Then, the cells were adjusted in $0.9 \%$ saline to $1 \times 10^{6} / \mathrm{mL}$ with $>95 \%$ viability tested by trypan blue. Finally, $2 \times 10^{5}$ cells of live H22 (0.2 mL for each mouse) was injected into the caudal vein. The survival status of the mice was recorded.

\section{Therapeutic regime of the models}

In this study, the drugs were given at two doses: $15 \mathrm{mg} / \mathrm{kg}$ (mouse body weight) (injected three times) in three groups; and $30 \mathrm{mg} / \mathrm{kg}$ (injected 6 times) in another three groups. On the 5th, 6th, and 7th day after the intravenous burden of $\mathrm{H} 22$ cells, $182 \mathrm{BALB} / \mathrm{c}$ mice (weighing $21.4 \pm 1.6 \mathrm{~g}$ ) in good condition were selected and randomly divided into seven groups (26 for each group), and they were caudal vein-injected daily with $0.4 \mathrm{~mL}$ of $0.9 \%$ saline (group A, control) or $0.4 \mathrm{~mL}$ of $0.9 \%$ saline solution containing PTX (group B1), M(PTX) (group C1), and FA-M(PTX) (group D1), respectively, for three times (once per day) with a total equivalent PTX dose of $15 \mathrm{mg} / \mathrm{kg}$; furthermore, on the 12th, 13th, and 14th day after the intravenous injection of $\mathrm{H} 22$ cells, the models in the PTX (group B2), M(PTX) (group C2), and FA-M(PTX) (group D2) groups were caudal vein-injected daily for three times, as above, with the final equivalent dose of PTX up to $30 \mathrm{mg} / \mathrm{kg}$.

\section{Evaluation of pulmonary metastasis inhibition}

On the 21st day after the injection of tumor cells, 42 mice were randomly selected (six mice from each group) 
and sacrificed. At necropsy, metastasis burden refers to the relative increase to the total lung weight. The excised lungs were weighed and the pulmonary metastasis colonies on the surface of the lungs were counted. Then, the excised lungs were fixed in a $4 \%$ paraformaldehyde solution overnight and processed for paraffin sections followed by an $\mathrm{HE}$ and IHC stain. The rest of the 140 mice were fed for the survival analysis.

\section{Immunohistochemistry assay}

This assay was conducted in accordance with the manufacturer's instructions. The IHC kit was purchased from Beijing Zhongshan Golden Bridge Biotechnology Co, Ltd, (Beijing, People's Republic of China). The paraffin slides of excised lung ( $4 \mu \mathrm{m}$ in thickness) were dewaxed following the avidin-biotin-peroxidase method (Vector ABC kit; Vector Laboratories, Burlingame, CA, USA). After blocking endogenous peroxidase with a $3 \%$ hydrogen peroxide solution for 15 minutes, the sections were boiled in $10 \mathrm{mM}$ citrate buffer ( $\mathrm{pH}$ 6.0) for 25 minutes and cooled for 20 minutes, then incubated overnight at $4^{\circ} \mathrm{C}$ with the primary antibody at a dilution of 1:50 of matrix metalloproteinase (MMP)-2 and 1:100 of MMP-9, respectively. Following this, the sections were incubated with biotinylated antirabbit immunoglobulin $\mathrm{G}$, which was diluted to 1:100 for 10 minutes followed by incubation with $\mathrm{ABC}$ at a dilution of 1:100 for 10 minutes at $22^{\circ} \mathrm{C}$. The peroxidase reaction was visualized with $0.05 \%$ diaminobenzidine as the coloring agent and $0.01 \%$ hydrogen peroxide; it was then counterstained with hematoxylin. Negative controls were stained without the primary antibody. Based on the cytoplasmic stain, the diffusiveness and intensity of the stain were semiquantitatively evaluated using an Olympus BX51 microscope (Olympus Corporation, Tokyo, Japan) to measure the mean gray values (the gray value is a measure of light brightness, expressed as a number from 0 ["black"] to 255 ["white"], which means that high gray scale values correspond to low immunoreaction intensities) using the Motic ${ }^{\circledR}$ Images Advanced 3.2 image analysis system (Ted Pella, Inc., Redding, CA, USA). The gray values at five random locations in the $400 \times$ micrograph of one lung section were averaged as the mean of one lung tissue.

\section{Hematoxylin and eosin (HE) staining of the tumor slices}

The tumor tissue fixed for 48 hours in a 4\% paraformaldehyde solution was dehydrated, embedded in rosin, sectioned, and stained with HE (HE kit; Sigma-Aldrich), and observed by light microscopy.

\section{Survival analysis}

The general conditions and death time of the remaining 140 mice bearing pulmonary metastatic hepatoma (20 in each group) were recorded daily for the survival analysis, which was censored on the 75th day after the intravenous burden of H22 cells. For the survival analysis, all of the mice were confirmed by necropsy and HE stain after they were sacrificed, and the models with confirmed lung metastasis colonies were included in this study. A total of $140 \mathrm{BALB} / \mathrm{c}$ mice in seven groups were used for the survival analysis. All of the mice used for the survival study with lung metastasis colonies were confirmed by necropsy and HE stain, which showed that the tumor-bearing success rate is up to $100 \%$ in this study.

\section{Statistical analysis}

Statistical analysis was performed using the Statistical Package for the Social Sciences (SPSS 16.0) for Windows software (IBM Corporation, Armonk, NY, USA). The data were presented as the mean $\pm \mathrm{SE}(\bar{x} \pm \mathrm{SE})$. Comparison of the data between the different groups was made by analysis of variance. Kaplan-Meier survival plots were generated, and comparisons between the survival curves were made with the log-rank test. $P<0.05$ was regarded as a statistically significant difference.

\section{Results}

\section{Preparation of M(PTX) and FA-M(PTX)}

As shown in Table S1, FA and PTX containing composite micelles (FA-M[PTX]) (PTX content $22.5 \mathrm{wt} \%$ ) were prepared by coassembling the $\mathrm{FA}$-polymer conjugate, MPEG-b-P(LA-co-DHP/FA) (FA content $1.4 \mathrm{wt} \%$ ) and PTX-polymer conjugate, poly(ethylene glycol)-bpoly(L-lactide-co-2-methyl-2-carboxyl-propylene carbonate/PTX) (MPEG-b-P[LA-co-DCC/PTX]) (PTX content $25 \mathrm{wt} \%$ ), with a mass ratio of 1:9. The morphologies of the M(PTX) and FA-M(PTX) micelles were observed by dynamic light scattering and TEM again (Table S1). The TEM images revealed that the micelles are dispersed as individuals with a well-defined spherical shape, and they were homogeneously distributed around $40 \sim 60 \mathrm{~nm}$ in diameter.

\section{Study in vitro}

\section{Cellular viability assay}

The cell viability of $\mathrm{H} 22$ incubated with PTX, M(PTX), and FA-M(PTX) for 12 hours, 24 hours, and 48 hours is 
depicted in Figure 1 as a function of the equivalent PTX concentration. Both dose-dependent and time-dependent cytotoxicity are observed. All the drugs are inhibitory to H22, as shown in Figure 1. Under most cases given in this study, there were no significant differences between
$\mathrm{M}(\mathrm{PTX})$ and FA-M(PTX) on H22 after incubation from 12 hours to 48 hours; moreover, it is indicated that pure PTX is the most efficacious among the three agents in vitro at 12 hours, as the half maximal inhibitory concentration $\left(\mathrm{IC}_{50}\right)$ of the $\mathrm{M}(\mathrm{PTX})$ and FA-M(PTX) is 4.01 and 3.54 times,

A

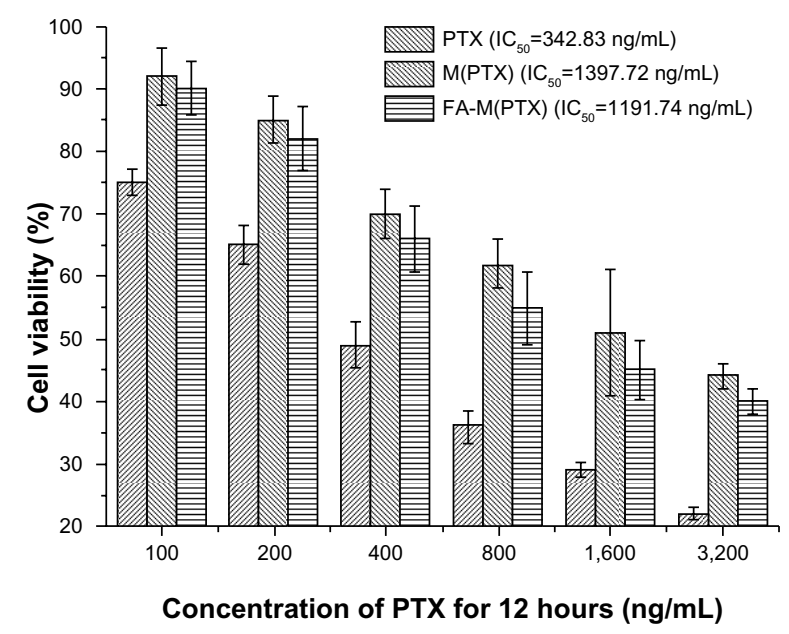

B

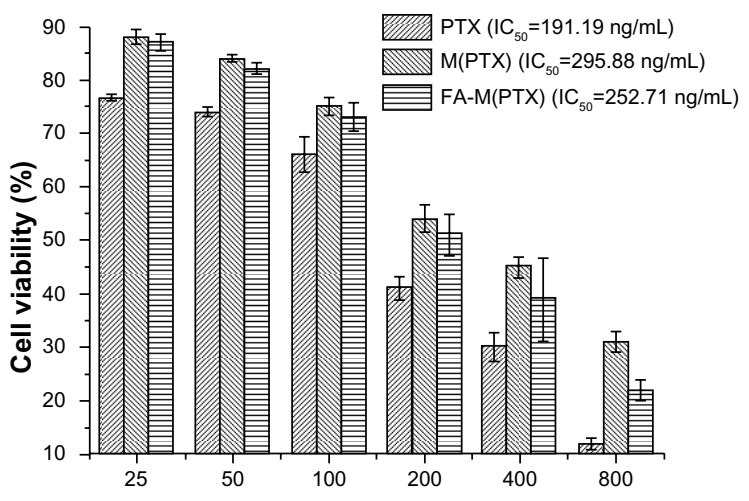

Concentration of PTX for 24 hours (ng/mL)

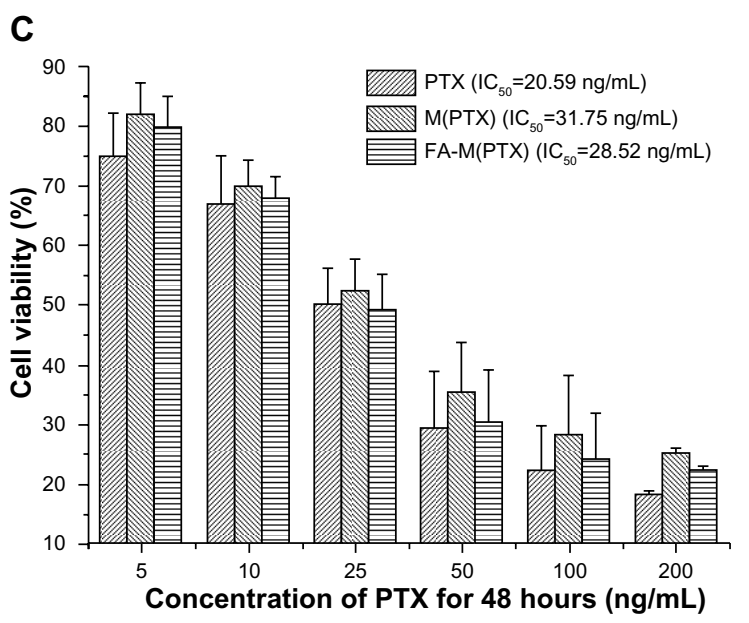

Figure I Viability of $\mathrm{H} 22$ cells after co-incubation with PTX, M(PTX), and FA-M(PTX) for 12 hours, 24 hours, and 48 hours, respectively. Notes: Cell viability of H22 cells after co-incubation with PTX, M(PTX), and FA-M(PTX) for (A) I 2 hours; (B) 24 hours; and (C) 48 hours. Abbreviations: PTX, paclitaxel; M(PTX), paclitaxel-containing micelles; FA-M(PTX), folic acid and paclitaxel-containing mixed micelles; $\mathrm{H} 22$, hepatoma 22. 
respectively, that of PTX (342.83 ng/mL). Nevertheless, the $\mathrm{IC}_{50}$ of the micelles is 1.55 and 1.32 times, respectively, that of PTX (191.19 ng/mL) at 24 hours; furthermore, the $\mathrm{IC}_{50}$ of the micelles showed obvious similarities at 48 hours compared with PTX $(20.59 \mathrm{ng} / \mathrm{mL})$, which demonstrated the theoretically controlled release of PTX from the micelles in RPMI 1640 medium in a time-dependent manner. For instance, the viability of $\mathrm{H} 22$ incubated with $100 \mathrm{ng} / \mathrm{mL}$ of PTX, M(PTX), and FA-M(PTX) is inhibited to $22 \%, 28 \%$, and $24 \%$, respectively, at 48 hours. However, the presumed preferential endocytosis of FA-conjugated micelles by $\mathrm{H} 22$ compared with the FA-free micelles was not indicated by cellular viability at the three time points given all the conditions in this study.

\section{Hoechst 33342/PI double-stain assay}

The blue fluorescent dye of Hoechst 33342 stains the condensed chromatin in apoptotic cells more brightly than normal chromatin, while the red fluorescent dye of PI is only permeant to dead cells. A simultaneous stain of the dyes could distinguish normal, apoptotic, and dead cell populations by FCM and fluorescence microscopy. The time-dependent apoptosis of $\mathrm{H} 22$ cells induced by the drugs was observed. As shown in Figure 2, the apoptosis of the drug groups was evidently higher when compared with the control at 24 hours and 72 hours. The mean apoptosis rate of PTX, M(PTX), and FA-M(PTX) was $16.8 \%, 8.8 \%$, and $11 \%$ at 24 hours, while it was up to $39.4 \%, 34.9 \%$, and $37.7 \%$ at 72 hours, respectively. There was a significant difference between PTX
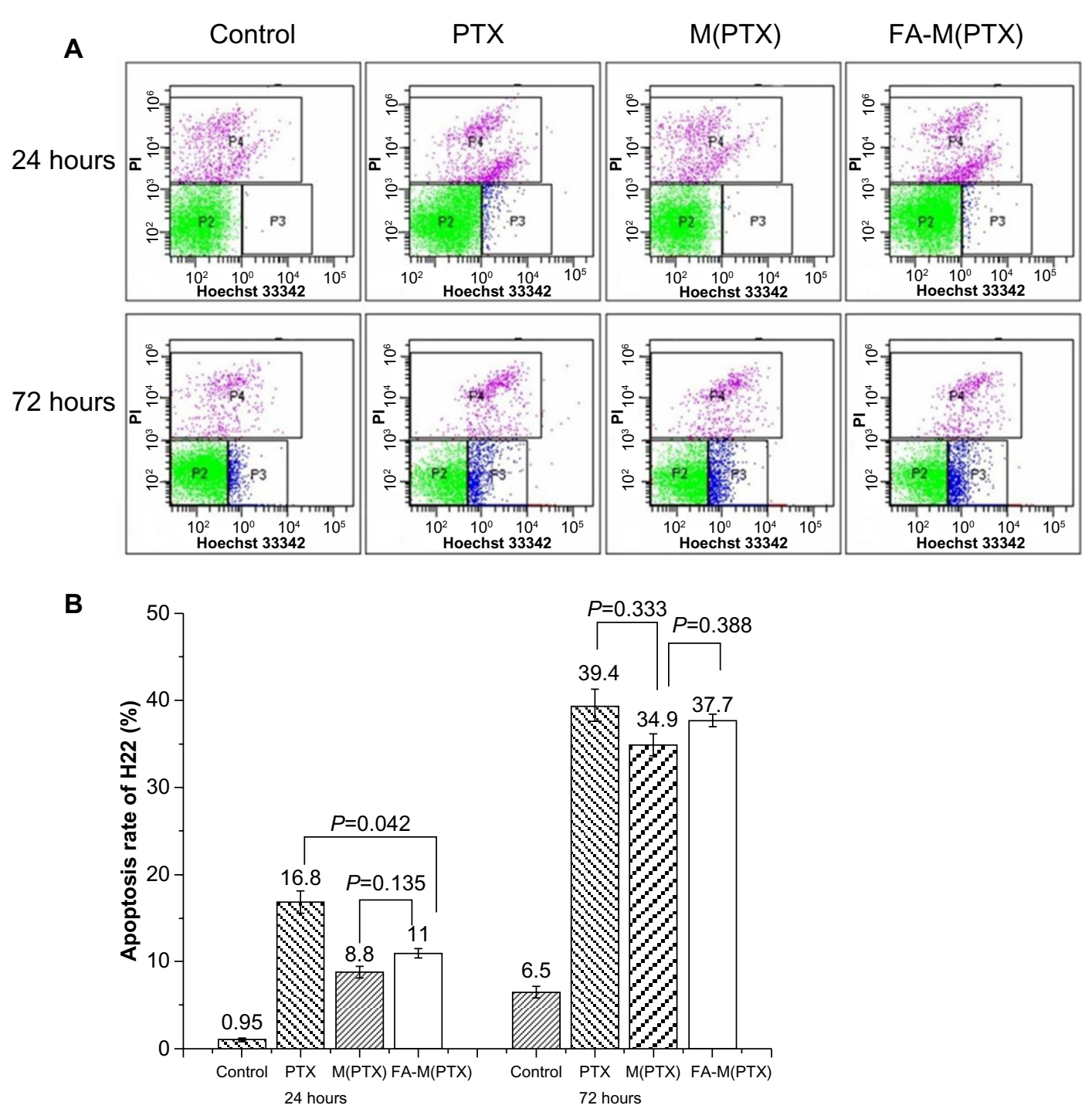

Figure 2 The apoptosis of $\mathrm{H} 22$ detected by FCM and the apoptosis of $\mathrm{H} 22$ detected by FCM after incubation with drugs for 24 hours and 72 hours. Notes: (A) The apoptosis of $\mathrm{H} 22$ detected by FCM; (B) the apoptosis of $\mathrm{H} 22$ detected by FCM after incubation with drugs for 24 hours and 72 hours. Abbreviations: PTX, paclitaxel; M(PTX), paclitaxel-containing micelles; FA-M(PTX), folic acid and paclitaxel-containing mixed micelles; H22, hepatoma 22; FCM, flow cytometry; PI, propidium iodide; P2, normal/live cells; P3, apoptosis cells; P4, necrotic cells. 
and the two micelles ( $P=0.006$ and $P=0.042$, respectively) at 24 hours, while there was not an obvious difference between $\mathrm{M}(\mathrm{PTX})$ and FA-M(PTX); however, there was no statistical difference among the three drugs at 72 hours. The data were in accordance with the results of the cellular viability assay; this may be ascribed to the controlled release of PTX from the micelles in the medium. In conclusion, the apoptosis of H22 induced by three drugs follows the order as $\mathrm{M}(\mathrm{PTX}) \leq \mathrm{FA}-$ $\mathrm{M}(\mathrm{PTX})<\mathrm{PTX}$ at 24 hours, while the following order was observed at 72 hours: $\mathrm{M}(\mathrm{PTX}) \leq \mathrm{FA}-\mathrm{M}(\mathrm{PTX}) \leq \mathrm{PTX}$.

\section{Cellular uptake of RhB-labeled micelles detected using flow cytometry}

The different uptake of the micelles by cancer cells and normal cells is important for the development of micelles as novel cancer therapeutic agents. The cellular uptake of the RhB-labeled FA-f-micelles and FA-mixed micelles was studied on HeLa, H22, and BEAS-2B cells to evaluate the role of FR-mediated endocytosis.

The three cell lines were exposed to $0.1 \%$ FA-f-micelles and FA-mixed micelles for 2 hours, respectively, and a quantitative analysis by FCM was performed. It is presumed and confirmed in this study that the cellular uptake of FA-mixed micelles was increased in HeLa and H22 cells with overexpressed FR when compared to nontumorigenic BEAS-2B cells. As shown in Figure 3, the obvious preferential uptake of FA-mixed micelles was shown in cancer cells (HeLa, $62.1 \%$; H22, 55.4\%) compared with BEAS-2B cells (37.6\%). Furthermore, an increased uptake of FA-f-micelles by HeLa (41.8\%) and H22 (40.1\%) was observed when compared with
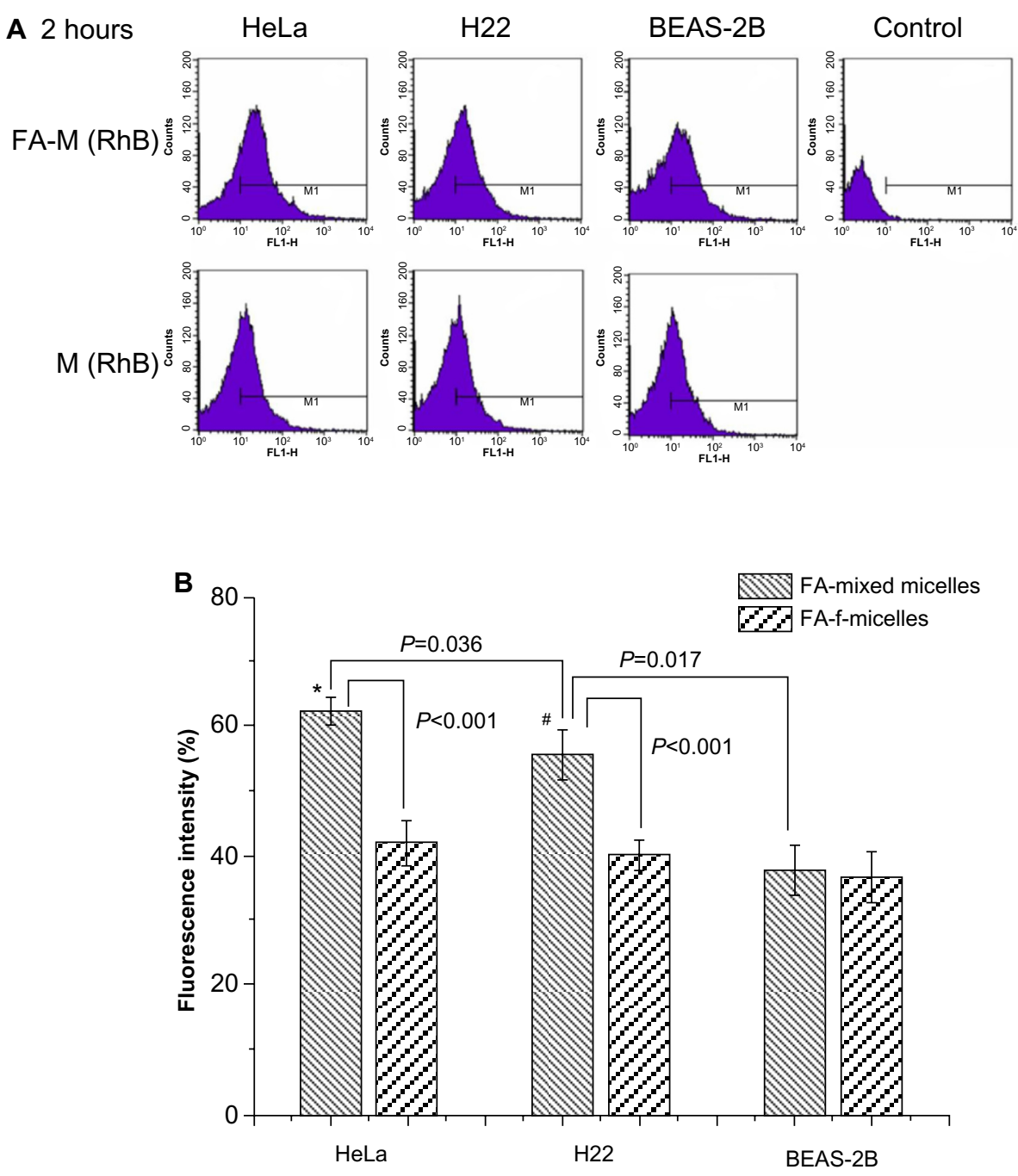

Figure 3 The fluorescence intensity detected by FCM and the uptake of RhB-labeled FA-f micelles and FA-mixed micelles for 2 hours.

Notes: (A) The fluorescence intensity detected by FCM; (B) the uptake of RhB-labeled FA-f-micelles and FA-mixed micelles for 2 hours. $* P=0.00$ I, compared with the uptake of FA-f-micelles by HeLa; ${ }^{*} P=0.024$, compared with the uptake of FA-f-micelles by $\mathrm{H} 22$.

Abbreviations: H22, hepatoma 22; FA-M, folic acid-containing composite micelles; RhB, rhodamine B; M, micelles; FA-f-micelles, folic acid-free copolymer micelles; FCM, flow cytometry. 
BEAS-2B (36.5\%). Statistically, HeLa and $\mathrm{H} 22$ revealed the enhanced cellular uptake of FA-mixed micelles compared with BEAS-2B $(P<0.001$ and $P=0.017$, respectively). Moreover, the uptake of FA-mixed micelles by the two cancer cells was significantly increased compared with that of FA-f-micelles $(P<0.001)$. In addition, HeLa showed the preferential uptake of FA-mixed-micelles compared with $\mathrm{H} 22$ $(P=0.036)$, which implicated FA-FR mediated endocytosis. In addition, the lower uptake of FA-f-micelles and FA-mixed micelles by normal bronchial cells compared with the cancer cells further supported the hypothesis of reduced side effects of PTX micelles compared with pure PTX.

\section{Study in vivo}

\section{Evaluation of pulmonary metastasis inhibition}

On the 21st day after intravenous injection of the H22 cells, 42 mice were randomly selected (six mice from each group) and sacrificed. The excised lungs were weighed, whereas the number of pulmonary metastasis colonies on the lung surface with high density and large size were uncountable because of fusion of the tumor nodules. However, the density of the metastatic colonies was visibly decreased in the drug groups compared with control. As shown in Figure 4, the ratio of wet lung weight to body weight in the drug groups was statistically decreased as an index of metastasis burden when compared with control $(P<0.05)$, and the ratio varied in an almost dose-related manner. Among these groups, the FA-M(PTX) displayed stronger efficacy than pure PTX and M(PTX) given equivalent doses of PTX at $15 \mathrm{mg} / \mathrm{kg}$

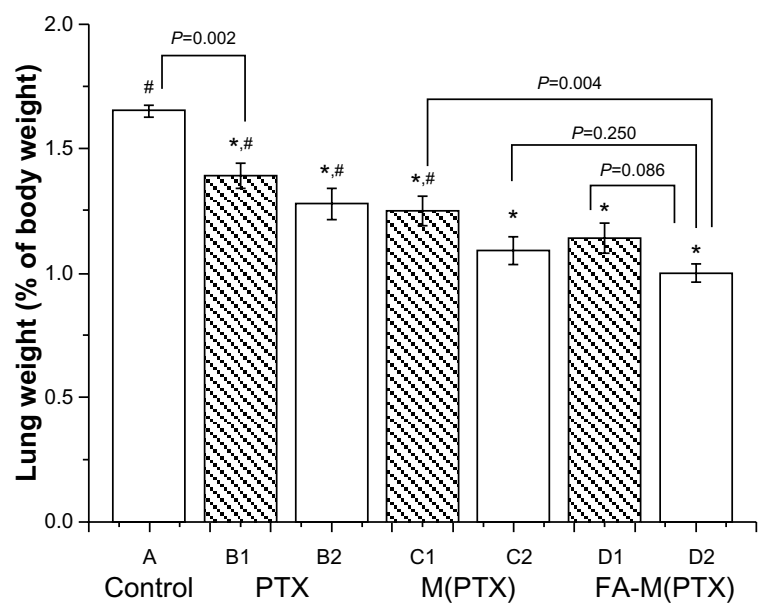

Figure 4 The wet lung weight (percentage of mice body weight).

Notes: $P$-values were calculated by Student's $t$-test $* P<0.05$, compared with control; ${ }^{\#} P<0.05$, compared with the D2 group. A, control; BI, paclitaxel $15 \mathrm{mg} / \mathrm{kg}$; B2, paclitaxel $30 \mathrm{mg} / \mathrm{kg}$; Cl, paclitaxel-containing mixed micelles $15 \mathrm{mg} / \mathrm{kg}$; C2, paclitaxelcontaining mixed micelles $30 \mathrm{mg} / \mathrm{kg}$; DI, folic acid and paclitaxel-containing mixed micelles $15 \mathrm{mg} / \mathrm{kg}$; D2, folic acid and paclitaxel-containing mixed micelles $30 \mathrm{mg} / \mathrm{kg}$. Abbreviations: PTX, paclitaxel; M(PTX), paclitaxel-containing micelles; FA$M(P T X)$, folic acid and paclitaxel-containing mixed micelles.
(A, B1, C1, and D1 groups) and $30 \mathrm{mg} / \mathrm{kg}$ (A, B2, C2, and D2 groups), respectively. Furthermore, among these groups, the pulmonary metastasis burden of the $\mathrm{D} 2$ group was evidently lower than that of the $\mathrm{A}, \mathrm{B} 1, \mathrm{~B} 2$, and $\mathrm{C} 1$ groups $(P=0.004)$ compared with the $\mathrm{C} 1$ group. Moreover, no significant differences were observed between $\mathrm{C} 2$ or D1 and D2 $(P=0.250$ and $P=0.086$, respectively). Based on these data, it is safe to conclude that the tumor pulmonary metastasis inhibition efficacy of M(PTX) as well as FA-M(PTX) are superior to pure PTX. However, the presumed enhanced inhibitory efficacy of FA-M(PTX) compared with M(PTX) was not observed in this metastasis burden evaluation.

\section{IHC and histopathological examination}

The expression of MMP-2/MMP-9 in 42 excised lungs was semiquantitatively evaluated by IHC. Following histomorphological examination by light microscope, the slides were assessed as computerized digital pictures to analyze the mean color intensity (ie, gray values) using ImagePlus software 3.2. After assessing different tissue areas or the cytoplasm within the pictures, the mean gray value per lung tissue was calculated, as reported. ${ }^{34}$

As shown in Figure 5 and Table 1, the microscopic tumor metastasis colonies detected by $\mathrm{HE}$ decreased in the drug groups in the order of PTX $<\mathrm{M}(\mathrm{PTX})<\mathrm{FA}-\mathrm{M}(\mathrm{PTX})$ when the equivalent dose of PTX is $15 \mathrm{mg} / \mathrm{kg}$ or $30 \mathrm{mg} / \mathrm{kg}$; furthermore, a dose-dependent therapeutic effect was indicated.

According to the instruction, high gray values correspond to low immunoreaction intensities - in other words, a low expression level of the proteins. As shown in Table 1, for MMP-2, the gray value of C1, C2, D1, and D2 was statistically higher compared with control $(P<0.05)$; moreover, the gray value of $\mathrm{D} 2$ was evidently more increased than that of the control, B1, B2, C1, and C2 $(P<0.05)$, respectively, which indicated that the expression of the MMP-2 protein on the lung tissues of the M(PTX) and FA-M(PTX) was obviously downregulated compared with control and PTX. Meanwhile, a dose-dependent effect was observed. For MMP-9, the gray value of C2, D1, and D2 was obviously increased compared with that of the control group; furthermore, the gray value of D2 was significantly higher than that of control, B1, B2, and C1 $(P<0.05)$, respectively. In conclusion, the expression of MMP-2 and MMP-9 were downregulated in the drug groups, and FA-M(PTX) demonstrated the most efficacious inhibition of the expression of MMP-2 and MMP-9, which implied that the FA-M(PTX) was superior than PTX and M(PTX) for the treatment of pulmonary metastatic hepatoma in vivo, given all the conditions in this study. 


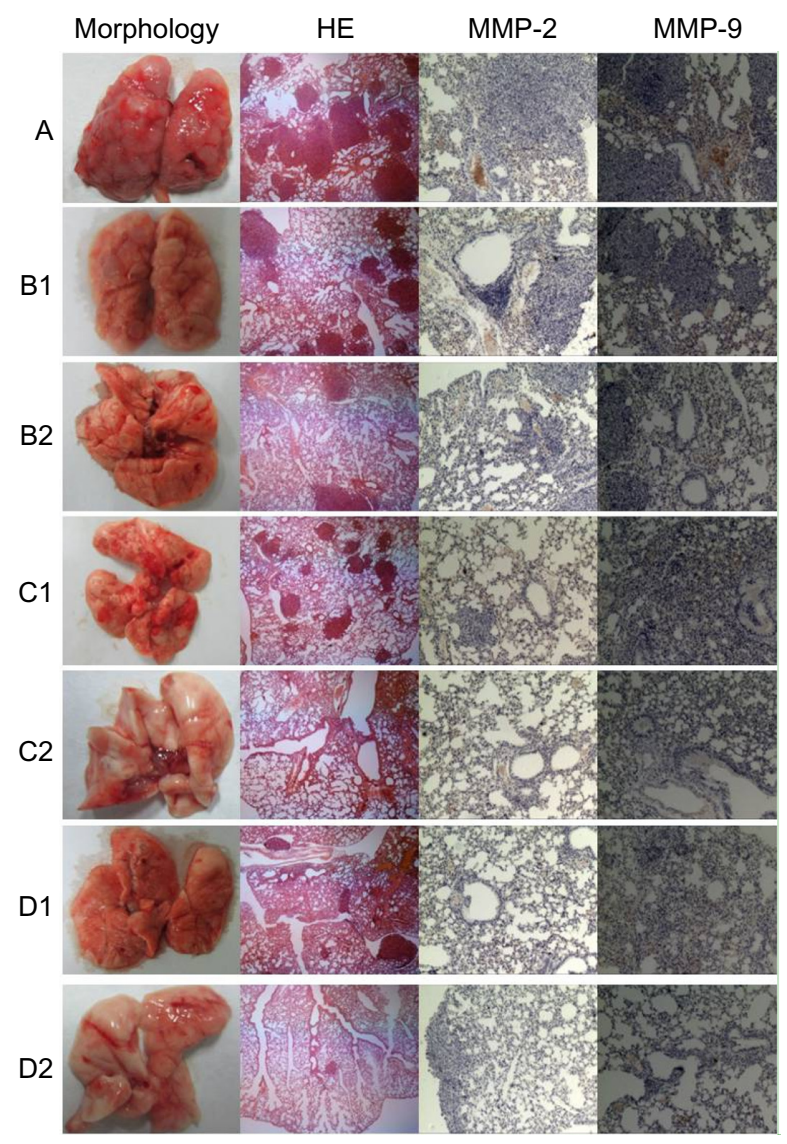

Figure 5 The lung tissues and micrographs of tumor sections stained with $\mathrm{HE}$, MMP-2, and MMP-9.

Notes: A, control; BI, paclitaxel $15 \mathrm{mg} / \mathrm{kg}$; B2, paclitaxel $30 \mathrm{mg} / \mathrm{kg}$; Cl, paclitaxelcontaining mixed micelles $15 \mathrm{mg} / \mathrm{kg}$; C2, paclitaxel-containing mixed micelles $30 \mathrm{mg} /$ $\mathrm{kg}$; DI, folic acid and paclitaxel-containing mixed micelles $15 \mathrm{mg} / \mathrm{kg}$; D2, folic acid and paclitaxel-containing mixed micelles $30 \mathrm{mg} / \mathrm{kg}$.

Abbreviations: HE, hematoxylin and eosin stain; MMP, matrix metalloproteinase.

\section{Survival analysis}

The Kaplan-Meier survival curve is shown in Figure 6. The median/mean survival time of the groups was compared using the log-rank test (Table 2). The mice in the drug groups showed a prolonged survival time compared with the control with equivalent doses of PTX of $15 \mathrm{mg} / \mathrm{kg}$ as well as $30 \mathrm{mg} / \mathrm{kg}$. The FA-M(PTX) was significantly more effective than pure PTX and M(PTX) on H22 pulmonary metastasis models.

As shown in Table 2, the mean survival time of mice in the $\mathrm{C} 1$ and D1 groups was prolonged compared with that in the B1 group, where the mice were given equivalent PTX doses of $15 \mathrm{mg} / \mathrm{kg}$; conversely, there were no significant difference between $\mathrm{C} 1$ and $\mathrm{D} 1(P=0.145)$. When given equivalent doses of PTX of $30 \mathrm{mg} / \mathrm{kg}$, the mean survival time of the $\mathrm{C} 2$ and $\mathrm{D} 2$ groups was prolonged compared with $\mathrm{B} 2$; moreover, the survival time of $\mathrm{D} 2$ was longer than that of $\mathrm{C} 2(P=0.01)$. Based on these data, it is concluded that FA-M(PTX) is more efficient
Table I Gray value of the sections by IHC on the 2 Ist day after intravenous injection of $\mathrm{H} 22$

\begin{tabular}{|c|c|c|c|}
\hline \multirow[t]{2}{*}{ Groups } & \multirow[t]{2}{*}{$\mathbf{n}$} & \multicolumn{2}{|c|}{ Gray value $(\bar{x} \pm S E)$} \\
\hline & & MMP-2 & MMP-9 \\
\hline$A$ & 6 & $168.3 \pm 5.7 \%$ & $167.8 \pm 5.3^{\# \#}$ \\
\hline BI & 6 & $174.0 \pm 5.0^{\#}$ & $174.2 \pm 1.8^{\#}$ \\
\hline B2 & 6 & $178.8 \pm 7.0^{\# \#}$ & $178.5 \pm 3.2^{\#}$ \\
\hline $\mathrm{Cl}$ & 6 & $183.0 \pm 2.9^{* . \#}$ & $177.8 \pm 7.5^{\#}$ \\
\hline $\mathrm{C} 2$ & 6 & $184.5 \pm 4.8^{*, \#}$ & $189.0 \pm 7.2^{*}$ \\
\hline DI & 6 & $187.0 \pm 5.0 *$ & $192.5 \pm 5.4^{* * . \Delta}$ \\
\hline D2 & 6 & $199.5 \pm 3.6 * *$ & $202.2 \pm 3.9 * *$ \\
\hline
\end{tabular}

Notes: For MMP- 2 and MMP-9 respectively, $* \mathrm{P}<0.05, * * \mathrm{P}<0.0$ l versus the $\mathrm{A}$ group; ${ }^{\#} P<0.05,{ }^{\prime} P<0.01$ versus the $D 2$ group; $\triangle P<0.05$ versus the $B I$ group. $A$, control group; $\mathrm{BI}$, paclitaxel $15 \mathrm{mg} / \mathrm{kg}$; B2, paclitaxel $30 \mathrm{mg} / \mathrm{kg}$; Cl, paclitaxel-containing mixed micelles at $15 \mathrm{mg} / \mathrm{kg}$; C2, paclitaxel-containing mixed micelles at $30 \mathrm{mg} / \mathrm{kg}$; DI, folic acid and paclitaxel-containing mixed micelles at $15 \mathrm{mg} / \mathrm{kg}$; D2, folic acid and paclitaxel-containing mixed micelles at $30 \mathrm{mg} / \mathrm{kg}$.

Abbreviations: IHC, immunohistochemistry; $\mathrm{H} 22$, hepatoma 22; n, number; SE, standard error; MMP, matrix metalloproteinase.

than PTX and M(PTX) in terms of the survival benefit for the pulmonary tumor metastasis mice models in this study. As for the dose-related analysis, the survival time of the B2 group was longer than that of the $\mathrm{B} 1$ group $(P=0.001)$, while the survival time of the $\mathrm{C} 2$ group was longer than that of the $\mathrm{C} 1$ group $(P=0.001)$. In addition, the $\mathrm{D} 2$ group showed a prolonged survival time when compared to that of the D1 group $(P=0.011)$, which implied that there was an obvious dose-dependent survival prolongation effect.

Normal tissues with restricted expression of FR could suffer reduced side effects compared with that of malignant tissues with overexpressed FR via FR-mediated endocytosis; ${ }^{24}$ furthermore, the adverse effects associated with polyoxyethylene castor oil as a solution of PTX are avoided, which may

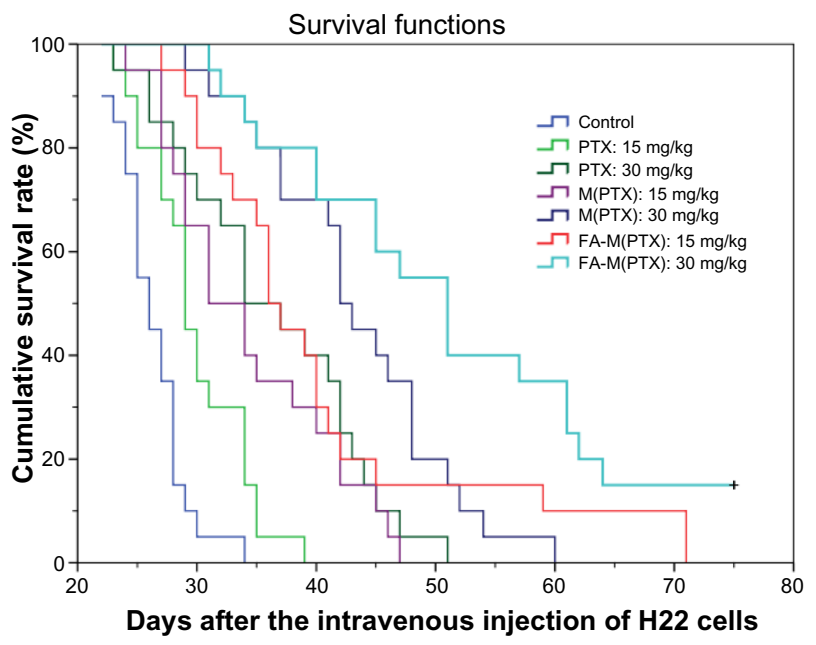

Figure 6 Kaplan-Meier survival curves of the $\mathrm{H} 22$ pulmonary metastasis mice. Abbreviations: PTX, paclitaxel; M(PTX), paclitaxel-containing micelles; FAM(PTX), folic acid and paclitaxel-containing mixed micelles; H22, hepatoma 22. 
Table 2 Median survival time and mean survival time of the mice

\begin{tabular}{|c|c|c|c|c|c|}
\hline Group & n & $\begin{array}{l}\text { Median } \pm \text { SE } \\
\text { (d) }\end{array}$ & $\begin{array}{l}95 \% \mathrm{Cl} \\
\text { (d) }\end{array}$ & $\begin{array}{l}\text { Mean } \pm \text { SE } \\
\text { (d) }\end{array}$ & $\begin{array}{l}95 \% \mathrm{Cl} \\
\text { (d) }\end{array}$ \\
\hline A & 20 & $26.0 \pm 1.1$ & $23.8 \sim 28.2$ & $26.3 \pm 0.6$ & $25.0 \sim 27.6$ \\
\hline $\mathrm{BI} *$ & 20 & $29.0 \pm 0.6$ & $27.9 \sim 30.1$ & $29.9 \pm 0.9$ & $28.0 \sim 31.7$ \\
\hline $\mathrm{B} 2 *, \mathbf{\Lambda}$ & 20 & $34.0 \pm 2.8$ & $28.5 \sim 39.5$ & $36.4 \pm 1.8$ & $32.9 \sim 39.8$ \\
\hline $\mathrm{Cl}^{*, \mathbf{\Delta} \Delta}$ & 20 & $31.0 \pm 2.2$ & $26.6 \sim 35.4$ & $34.4 \pm 1.6$ & $31.2 \sim 37.5$ \\
\hline $\mathrm{C} 2^{*, \boldsymbol{\Lambda}, \#, \Delta}$ & 20 & $42.0 \pm 1.1$ & $39.8 \sim 44.2$ & $43.3 \pm 1.8$ & $39.8 \sim 46.7$ \\
\hline $\mathrm{DI} *, \mathbf{\Delta}$ & 20 & $36.0 \pm 1.1$ & $33.8 \sim 38.2$ & $40.5 \pm 2.8$ & $34.9 \sim 46.0$ \\
\hline $\mathrm{D} 2 *, \mathbf{\Lambda}, \#, \Delta$ & 20 & $51.0 \pm 2.9$ & $45.3 \sim 56.7$ & $51.6 \pm 3.1$ & $45.5 \sim 57.7$ \\
\hline
\end{tabular}

Notes: Log-rank test (Mantel-Cox): $* P<0.01$ compared with the A group; $\triangle P<<0.0$ I, $\Delta \Delta P<0.05$ ( $P=0.015)$ compared with the $B \mid$ group; $\# P<0.01$ compared with the $B 2$ group; $\triangle P<0.01$ compared with the $C 1$ group; $C 2$ versus $D 2, P=0.01$; $D 1$ versus $\mathrm{D} 2, P=0.01 \mathrm{I}$. A, control; $\mathrm{BI}$ and $\mathrm{B} 2$ groups, pure PTX at $15 \mathrm{mg} / \mathrm{kg}$ and $30 \mathrm{mg} / \mathrm{kg}$, respectively; $\mathrm{Cl}$ and $\mathrm{C2}, \mathrm{M}(\mathrm{PTX})$ groups with a equivalent $\mathrm{PTX}$ dose of $15 \mathrm{mg} / \mathrm{kg}$ and $30 \mathrm{mg} / \mathrm{kg}$, respectively; DI and D2, FA-M(PTX) groups with a equivalent PTX dose of $15 \mathrm{mg} / \mathrm{kg}$ and $30 \mathrm{mg} / \mathrm{kg}$, respectively.

Abbreviations: $n$, number; SE, standard error; $\mathrm{Cl}$, confidence interval; PTX, paclitaxel; $M(P T X)$, paclitaxel-containing micelles; FA-M(PTX), folic acid and paclitaxel-containing mixed micelles.

be partly ascribed to the prolonged survival of the mice in the micelle groups. In addition, Parker et a ${ }^{35}$ evaluated the folate receptor expression using a radioligand binding assay, and they indicated that the FR expression in the normal lung tissue of BALB/c mice was negligible. As shown in vitro in this study, the lower uptake of FA-f-micelles as well as of FA-mixed micelles by normal bronchial cells compared with the cancer cells further support reduced side effects and the prolonged survival time of mice in the PTX micelles group.

It is noted that three kinds of PTX drugs display different orders of antitumor ability: $\mathrm{M}(\mathrm{PTX}) \leq \mathrm{FA}-\mathrm{M}(\mathrm{PTX}) \leq \mathrm{PTX}$ in vitro and $\mathrm{PTX}<\mathrm{M}(\mathrm{PTX})<\mathrm{FA}-\mathrm{M}(\mathrm{PTX})$ in vivo. It is indicated that pure PTX is often captured by the reticuloendothelial system as a foreign invader before it enters the cancer cells, while FA-M(PTX) displays enhanced antitumor efficacy for FR-mediated endocytosis and its protection for PTX in micelles which shield it from the reticuloendothelial system.

\section{Discussion}

The cellular viability and FCM assay showed that pure PTX is the most efficacious agent in vitro (Figures 1 and 2). This is probably because the pure PTX diffuses into the cancer cells more efficiently than M(PTX) or FA-M(PTX). Another possibility is that pure PTX is effective once it enters the cells, while PTX - conjugated and trapped in the micelles - has to undergo a process of controlled release.

As shown in Figure 3, it is safe to conclude that the FR of tumor cells plays an important role via specific ligand-receptor-mediated endocytosis, which was evident by the differential uptake of RhB-labeled micelles that was paralleled with the FR expression level on the cells. Based on the data above, the treatment target should be properly selected according to the folate receptor's expression level, which provided a theoretical basis for clinical chemotherapy regimens for malignant tumors.

The process of the establishment of hematogenous metastasis consists of multiple distinct steps, as previously reported. ${ }^{36}$ MMPs degrade the extracellular matrix required for tumor invasion, metastasis, and tumor angiogenesis. ${ }^{37}$ Furthermore, the vascular endothelial growth factor, basic fibroblast growth factor, or transforming growth factor-b are induced or activated by MMPs, triggering the angiogenic switch during carcinogenesis and facilitating vascular remodeling and neovascularization at distant sites. ${ }^{38,39}$ The IHC assay indicated that the administration of PTX leads to the downregulation of MMP-2 and MMP-9 when compared with control, which may contribute to the decreased lung metastasis colonies. Besides, the expressions of these proteins are paralleled to the data of wet lung weight (percent to body weight). In conclusion, the relationship of MMP-2/MMP-9 and tumor pulmonary metastasis is applicable to the case of $\mathrm{H} 22$ cells.

The three drug formulations inhibit pulmonary metastasis of $\mathrm{H} 22$, which may account for the downregulated expression of MMP-2 and MMP-9; furthermore, it is also in accordance with the decreased lung metastasis colonies and prolonged survival time noted in mice. Furthermore, FA-M(PTX) demonstrated greater efficacy than pure PTX and simple PTX micelles for the inhibition of hematoma lung metastasis.

\section{Conclusion}

Bifunctional FA-M(PTX) represented enhanced inhibitory efficacy when compared to pure PTX and M(PTX) for intravenously injected $\mathrm{H} 22$ on BALB/c mice models, which is theoretically ascribed to FR-mediated endocytosis. Additionally, the extensive pulmonary capillary networks may play a role via the presumed prolonged circulation of the micelles which needs to be further certified effect. It is indicated that FA-M(PTX) is a promising antimetastatic therapeutic agent, and that FA-conjugated micelles are a preferential targeted delivery system when compared to micelles without FA.

\section{Acknowledgments}

The authors are thankful to the National Natural Science Foundation of China for financial support (Project no 20674084, 21004062, and 51103148), and the Ministry of Science and Technology of China ("973 Project"; no 2009CB930102; “863 Project”, no 2007AA03Z535).

\section{Disclosure}

The authors report no conflicts of interest in this work. 


\section{References}

1. Jemal A, Bray F, Center MM, Ferlay J, Ward E, Forman D. Global cancer statistics. CA Cancer J Clin. 2011;61(2):69-90.

2. Chen F, Sato K, Fujinaga T, et al. Pulmonary resection for metastases from hepatocellular carcinoma. World J Surg. 2008;32(10):2213-2217.

3. Rahbari NN, Mehrabi A, Mollberg NM, et al. Hepatocellular carcinoma: current management and perspectives for the future. Ann Surg. 2011;253(3):453-469.

4. Santel A, Aleku M, Röder N, et al. Atu027 prevents pulmonary metastasis in experimental and spontaneous mouse metastasis models. Clin Cancer Res. 2010;16(22):5469-5480.

5. Katyal S, Oliver JH 3rd, Peterson MS, Ferris JV, Carr BS, Baron RL. Extrahepatic metastases of hepatocellular carcinoma. Radiology. 2000;216(3):698-703

6. Natsuizaka M, Omura T, Akaike T, et al. Clinical features of hepatocellular carcinoma with extrahepatic metastases. J Gastroenterol Hepatol. 2005;20(11):1781-1787.

7. Yeo W, Mok TS, Zee B, et al. A randomized phase III study of doxorubicin versus cisplatin/interferon alpha-2b/doxorubicin/fluorouracil (PIAF) combination chemotherapy for unresectable hepatocellular carcinoma. J Natl Cancer Inst. 2005;97(20):1532-1538.

8. Gish RG, Porta C, Lazar L, et al. Phase III randomized controlled trial comparing the survival of patients with unresectable hepatocellular carcinoma treated with nolatrexed or doxorubicin. J Clin Oncol. 2007;25(21):3069-3075.

9. Ramanathan RK, Belani CP, Singh DA, et al. A phase II study of lapatinib in patients with advanced biliary tree and hepatocellular cancer. Cancer Chemother Pharmacol. 2009;64(4):777-783.

10. Giantonio BJ, Levy DE, O'dwyer PJ, Meropol NJ, Catalano PJ, Benson AB; Eastern Cooperative Oncology Group. A phase II study of high-dose bevacizumab in combination with irinotecan, 5-fluorouracil, leucovorin, as initial therapy for advanced colorectal cancer: results from the Eastern Cooperative Oncology Group study E2200. Ann Oncol. 2006;17(9):1399-1403.

11. Endicott JA, Ling V. The biochemistry of P-glycoprotein-mediated multidrug resistance. Annu Rev Biochem. 1989;58:137-171.

12. Park JG, Lee SK, Hong IG, et al. MDR1 gene expression: its effect on drug resistance to doxorubicin in human hepatocellular carcinoma cell lines. J Natl Cancer Inst. 1994;86(9):700-705.

13. Ng IO, Liu CL, Fan ST, Ng M. Expression of P-glycoprotein in hepatocellular carcinoma. A determinant of chemotherapy response. Am J Clin Pathol. 2000;113(3):355-363.

14. Zhou Q, Ching AK, Leung WK, et al. Novel therapeutic potential in targeting microtubules by nanoparticle albumin-bound paclitaxel in hepatocellular carcinoma. Int J Oncol. 2011;38(3):721-731.

15. Vessella RL, Pantel K, Mohla S. Tumor cell dormancy: an NCI workshop report. Cancer Biol Ther. 2007;6(9):1496-1504.

16. Sawyer TK. Cancer metastasis therapeutic targets and drug discovery: emerging small-molecule protein kinase inhibitors. Expert Opin Investig Drugs. 2004;13(1):1-19.

17. Okano J, Nagahara T, Matsumoto K, Murawaki Y. The growth inhibition of liver cancer cells by paclitaxel and the involvement of extracellular signal-regulated kinase and apoptosis. Oncol Rep. 2007;17(5):1195-1200.

18. Dandekar P, Jain R, Stauner T, et al. A hydrophobic starch polymer for nanoparticle-mediated delivery of docetaxel. Macromol Biosci. 2012;12(2):184-194.

19. Zhigaltsev IV, Winters G, Srinivasulu M, et al. Development of a weakbase docetaxel derivative that can be loaded into lipid nanoparticles. $J$ Control Release. 2010;144(3):332-340.

20. Sparreboom A, Scripture CD, Trieu V, et al. Comparative preclinical and clinical pharmacokinetics of a cremophor-free, nanoparticle albuminbound paclitaxel (ABI-007) and paclitaxel formulated in Cremophor (Taxol). Clin Cancer Res. 2005;11(11):4136-4143.
21. Prabaharan M, Grailer JJ, Pilla S, Steeber DA, Gong S. Folateconjugated amphiphilic hyperbranched block copolymers based on Boltorn H40, poly(L-lactide) and poly(ethylene glycol) for tumortargeted drug delivery. Biomaterials. 2009;30(16):3009-3019.

22. Lin JJ, Chen JS, Huang SJ, et al. Folic acid-Pluronic F127 magnetic nanoparticle clusters for combined targeting, diagnosis, and therapy applications. Biomaterials. 2009;30(28):5114-5124.

23. Li JW, Yang LW, Zhou ZF, et al. Mechanically stiffened and thermally softened Raman modes of ZnO crystal. J Phys Chem B. 2010;114(4): 1648-1651.

24. Kamen BA, Smith AK. A review of folate receptor alpha cycling and 5-methyltetrahydrofolate accumulation with an emphasis on cell models in vitro. Adv Drug Deliv Rev. 2004;56(8):1085-1097.

25. Park EK, Lee SB, Lee YM. Preparation and characterization of methoxy poly(ethylene glycol)/poly(epsilon-caprolactone) amphiphilic block copolymeric nanospheres for tumor-specific folate-mediated targeting of anticancer drugs. Biomaterials. 2005;26(9):1053-1061.

26. Wang J, Liu W, Tu Q, et al. Folate-decorated hybrid polymeric nanoparticles for chemically and physically combined paclitaxel loading and targeted delivery. Biomacromolecules. 2011;12(1):228-234.

27. Xie Z, Hu X, Chen X, Sun J, Shi Q, Jing X. Synthesis and characterization of novel biodegradable poly(carbonate ester)s with photolabile protecting groups. Biomacromolecules. 2008;9(1):376-380.

28. Hu X, Liu S, Huang Y, Chen X, Jing X. Biodegradable block copolymer-doxorubicin conjugates via different linkages: preparation, characterization, and in vitro evaluation. Biomacromolecules. 2010;11(8):2094-2102.

29. Wu W, Zheng Y, Wang R, et al. Antitumor activity of folate-targeted, paclitaxel-loaded polymeric micelles on a human esophageal EC9706 cancer cell line. Int J Nanomedicine. 2012;7:3487-3502.

30. Zhu Z, Xie C, Liu Q, et al. The effect of hydrophilic chain length and iRGD on drug delivery from poly( $\varepsilon$-caprolactone)-poly(N-vinylpyrrolidone) nanoparticles. Biomaterials. 2011;32(35):9525-9535.

31. Li Q, Zhu J, Sun F, Liu L, Liu X, Yue Y. Oncostatin M promotes proliferation of ovarian cancer cells through signal transducer and activator of transcription 3. Int J Mol Med. 2011;28(1):101-108.

32. Ma P, Liu S, Huang Y, Chen X, Zhang L, Jing X. Lactose mediated livertargeting effect observed by ex vivo imaging technology. Biomaterials. 2010;31(9):2646-2654.

33. Royal Society for the Prevention of Cruelty to Animals [webpage on the Internet]. Animal Protection Law of the People's Republic of China (Draft). December 16, 2009. Available from: http://blog.china.com.cn/ home.php? mod $=$ space $\&$ uid $=1235808 \&$ do $=$ blog\&id=198117. Accessed March 31, 2014.

34. Wehbrink D, Hässig M, Ritter N, Zerbe H, Bleul U, Boos A. Immunohistochemical demonstration of cyclooxygenase-2 (COX-2) and prostaglandin receptors EP2 and FP expression in the bovine intercaruncular uterine wall around term. Anim Reprod Sci. 2008;106(3-4):241-254.

35. Parker N, Turk MJ, Westrick E, Lewis JD, Low PS, Leamon CP. Folate receptor expression in carcinomas and normal tissues determined by a quantitative radioligand binding assay. Anal Biochem. 2005;338(2): 284-293.

36. Valastyan S, Weinberg RA. Tumor metastasis: molecular insights and evolving paradigms. Cell. 2011;147(2):275-292.

37. Ogata Y, Matono K, Nakajima M, et al. Efficacy of the MMP inhibitor MMI270 against lung metastasis following removal of orthotopically transplanted human colon cancer in rat. Int J Cancer. 2006;118(1):215-221.

38. Belotti D, Paganoni P, Manenti L, et al. Matrix metalloproteinases (MMP9 and MMP2) induce the release of vascular endothelial growth factor (VEGF) by ovarian carcinoma cells: implications for ascites formation. Cancer Res. 2003;63(17):5224-5229.

39. Bergers G, Brekken R, McMahon G, et al. Matrix metalloproteinase-9 triggers the angiogenic switch during carcinogenesis. Nat Cell Biol. 2000;2(10):737-744. 


\section{Supplementary materials}

Table SI Characteristics of M(PTX) and FA-M(PTX)

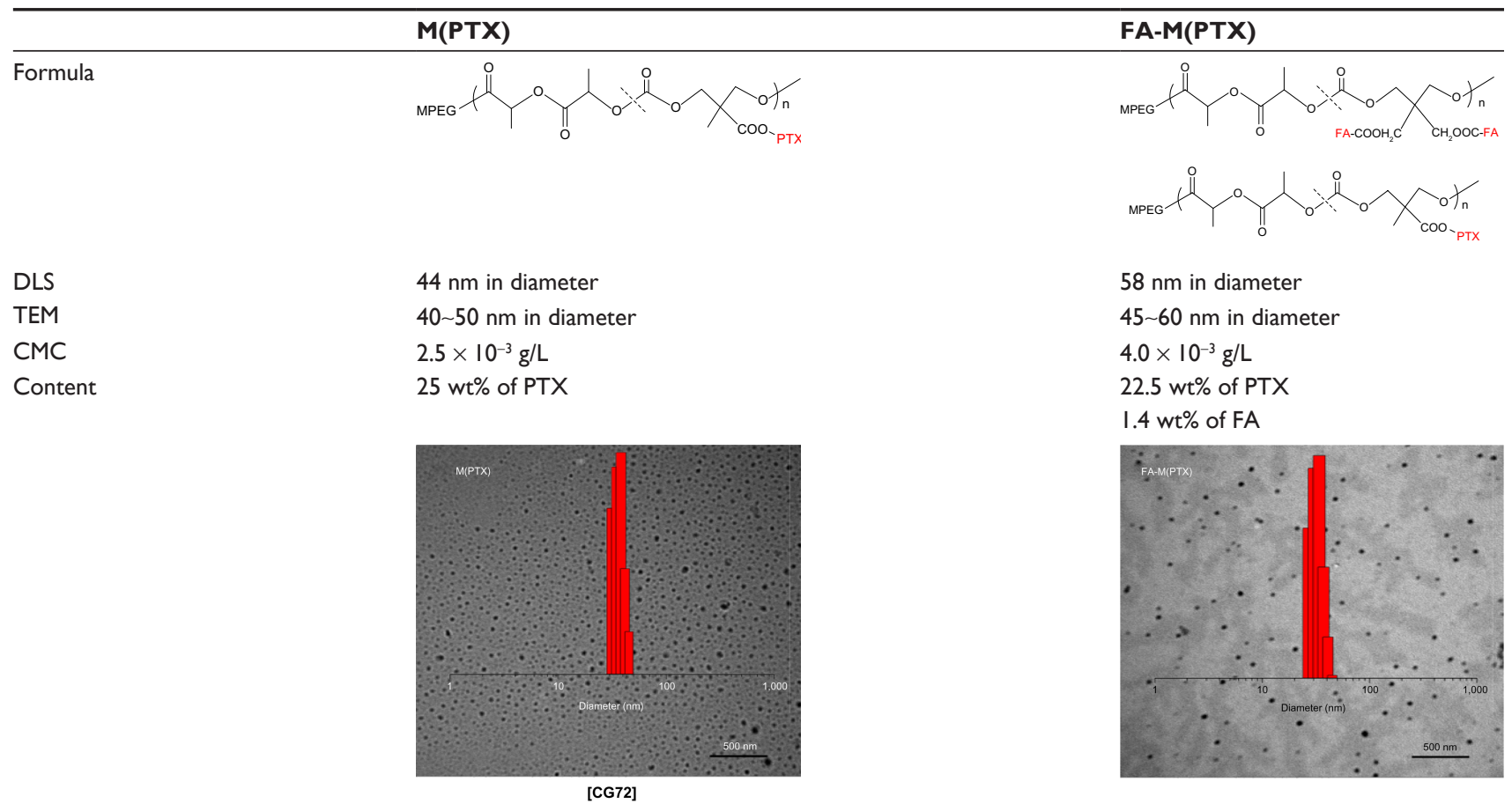

Abbreviations: M(PTX), paclitaxel-containing micelles; FA-M(PTX), folic acid and paclitaxel-containing micelles; DLS, dynamic light scattering; TEM, transmission electron microscopy; CMC, critical micelle concentration; PTX, paclitaxel; FA, folic acid.

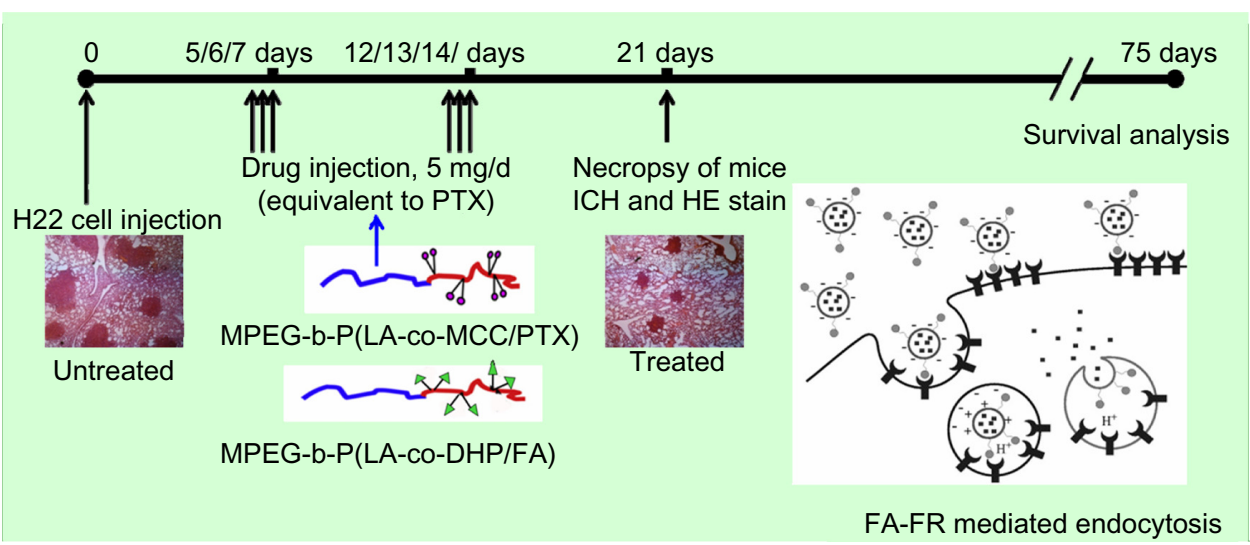

Figure SI The procedure of this study in vivo.

Abbreviations: PTX, paclitaxel; ICH, immunohistochemistry; HE, hematoxylin and eosin; H22, hepatoma 22; MPEG-b-P(LA-co-MCC/PTX), poly(ethylene glycol)-blockpoly(I-lactide-co-2-methyl-2-carboxyl-propylene carbonate/paclitaxel); MPEG-b-P(LA-co-DHP/FA), poly(ethylene glycol)-block-poly(lactide-co-2,2-dihydroxymethylpropylene carbonate/folic acid); FA, folic acid; FR, folate receptor.

\section{Publish your work in this journal}

The International Journal of Nanomedicine is an international, peerreviewed journal focusing on the application of nanotechnology in diagnostics, therapeutics, and drug delivery systems throughout the biomedical field. This journal is indexed on PubMed Central, MedLine, CAS, SciSearch ${ }^{\circledR}$, Current Contents ${ }^{\circledR} /$ Clinical Medicine,
Journal Citation Reports/Science Edition, EMBase, Scopus and the Elsevier Bibliographic databases. The manuscript management system is completely online and includes a very quick and fair peer-review system, which is all easy to use. Visit http://www.dovepress.com/ testimonials.php to read real quotes from published authors. 